\title{
Ruthenium metathesis catalysts containing chelating aryloxide ligands
}

\author{
Sebastien Monfette and Deryn E. Fogg*
}

Center for Catalysis Research and Innovation, Department of Chemistry, University of Ottawa, 10 Marie Curie, Ottawa, ON, Canada, KIN 6N5.

\section{SUPPORTING INFORMATION:}

\section{Contents:}

1. Spectra for RuXX'(IMes) $(\mathrm{py})(=\mathrm{CHPh})\left(\mathbf{5}: \mathrm{XX}^{\prime}=\right.$ 3,5-dichloro-2-

oxidobenzenesulfonate)
a. $\quad{ }^{1} \mathrm{H}$ NMR spectrum $\left(500 \mathrm{MHz}, \mathrm{C}_{6} \mathrm{D}_{6}\right)$
b. ${ }^{1} \mathrm{H}^{-13} \mathrm{C}$ HMQC NMR (500 MHz, $\left.\mathrm{C}_{6} \mathrm{D}_{6}\right)$
c. ${ }^{1} \mathrm{H}^{-13} \mathrm{C}$ HMBC NMR (500 MHz, $\left.\mathrm{C}_{6} \mathrm{D}_{6}\right)$

2. Spectra for $\mathrm{Ru}\left(o-\mathrm{O}_{2} \mathrm{C}_{6} \mathrm{H}_{4}\right)(\mathrm{IMes})(\mathrm{py})(=\mathrm{CHPh})(\mathbf{6})$
a. ${ }^{1} \mathrm{H}$ NMR spectrum $\left(300 \mathrm{MHz}, \mathrm{CDCl}_{3}\right)$
b. ${ }^{13} \mathrm{C}$ NMR spectrum $\left(75 \mathrm{MHz}, \mathrm{CDCl}_{3}\right)$ 
1a. ${ }^{1} \mathrm{H}$ NMR spectrum of $5\left(500 \mathrm{MHz}, \mathrm{C}_{6} \mathrm{D}_{6}\right)$

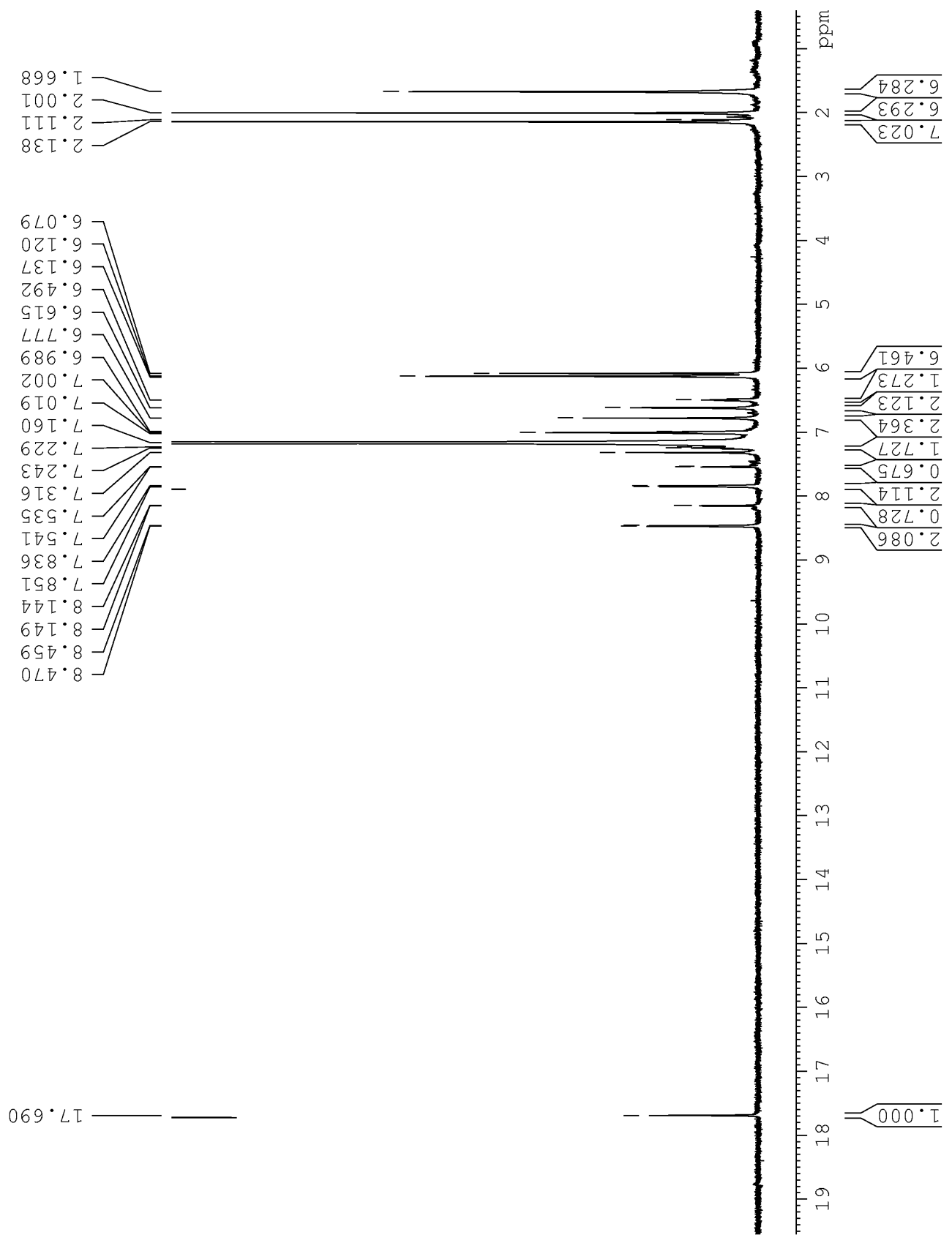


1b. ${ }^{1} \mathrm{H}-{ }^{13} \mathrm{C}$ HMQC spectrum of $5\left(500 \mathrm{MHz}, \mathbf{C}_{6} \mathbf{D}_{6}\right) \cdot{ }^{13} \mathrm{C}$ NMR signals are inferred from the projection of the cross-peaks; see text. Asterisk denotes solvent impurity.

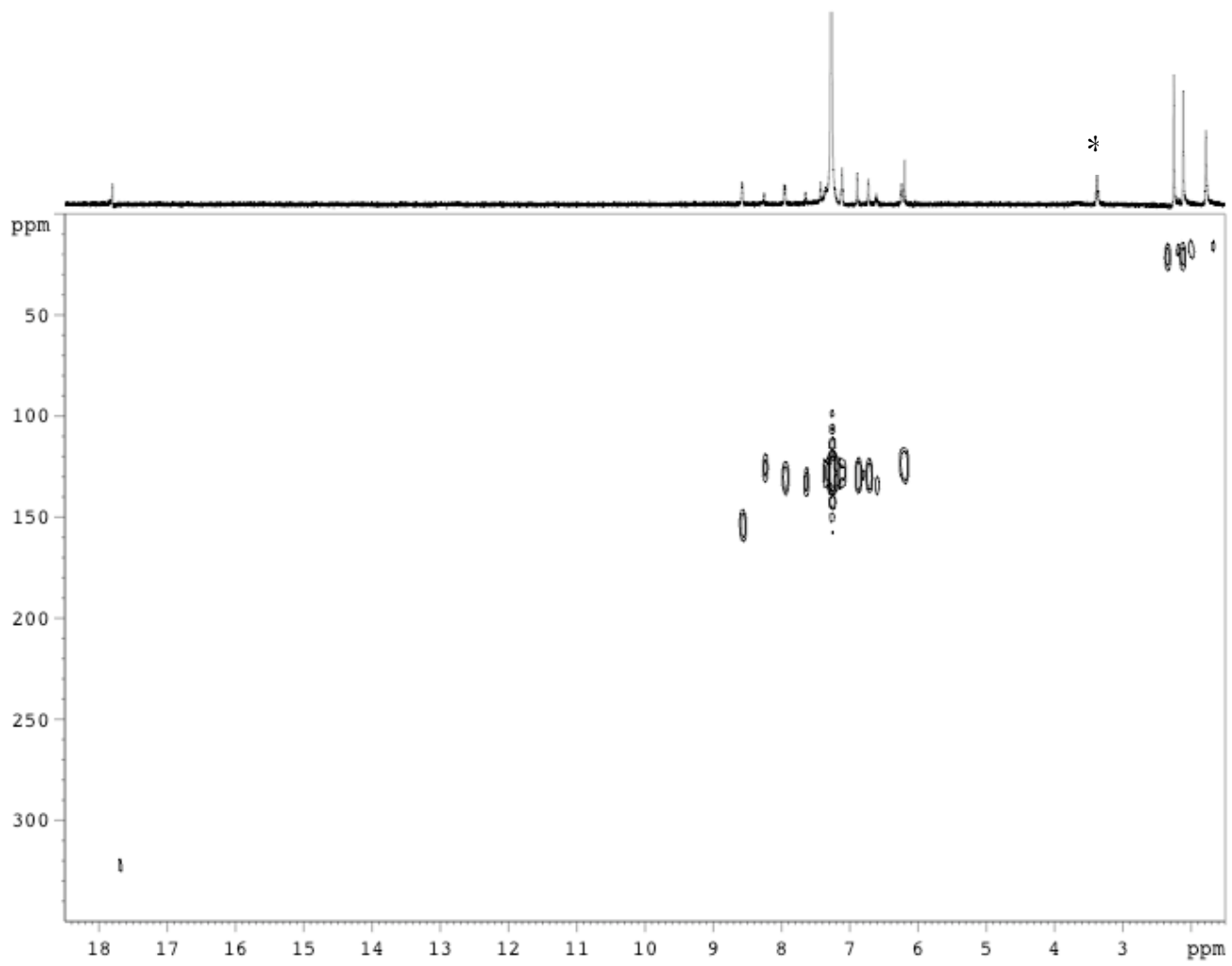


1c. ${ }^{1} \mathrm{H}^{-13} \mathrm{C}$ HMBC spectrum of $5\left(500 \mathrm{MHz}, \mathrm{C}_{6} \mathrm{D}_{6}\right)$. For convenience, the $\mathrm{F} 1$ trace is given as the projection of the cross-peaks. ${ }^{13} \mathrm{C}$ NMR signals are inferred from the projection of the crosspeaks; see text.

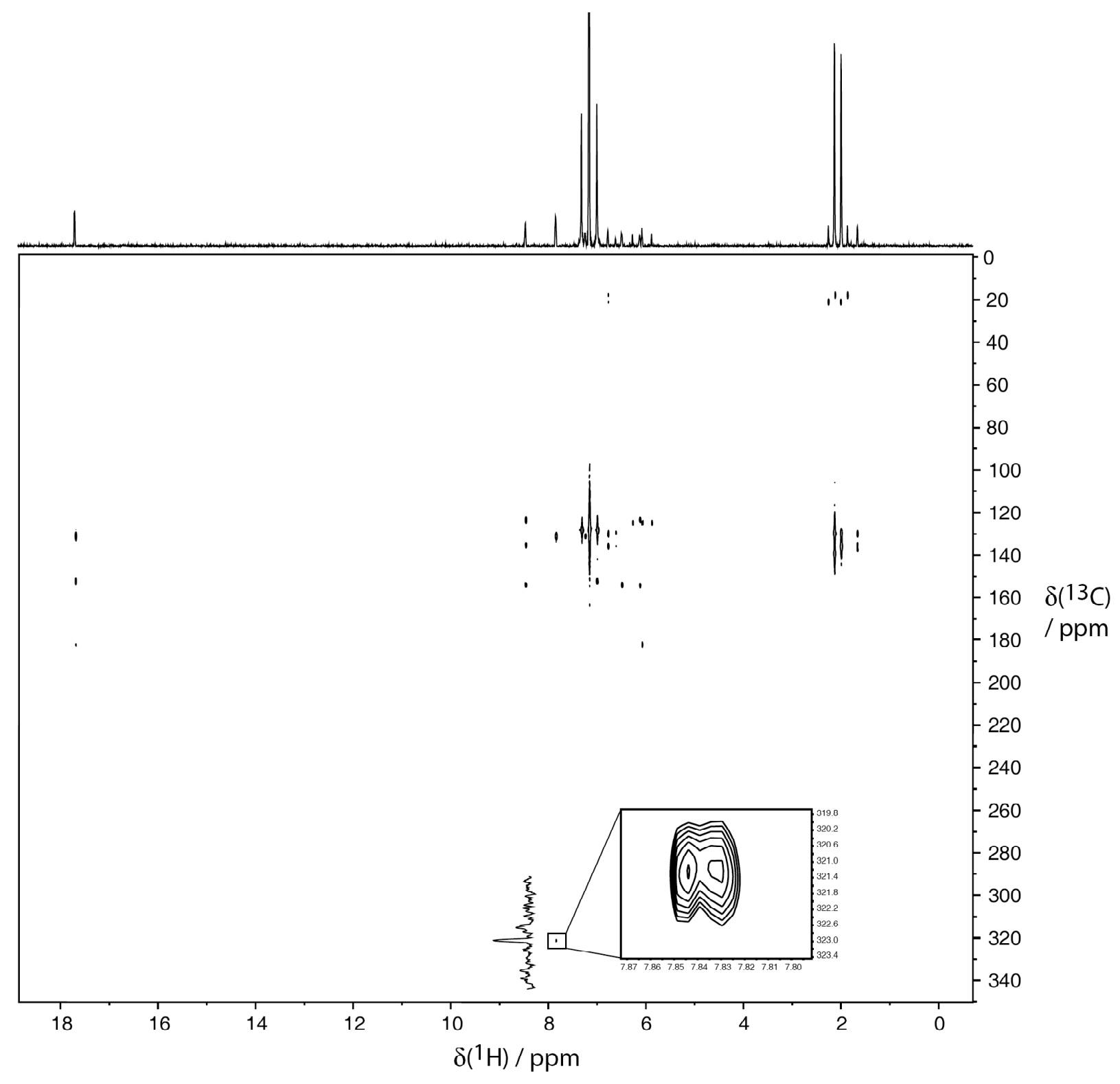


2a. ${ }^{1} \mathrm{H}$ NMR spectrum of $6\left(300 \mathrm{MHz}, \mathrm{CDCl}_{3}\right)$.

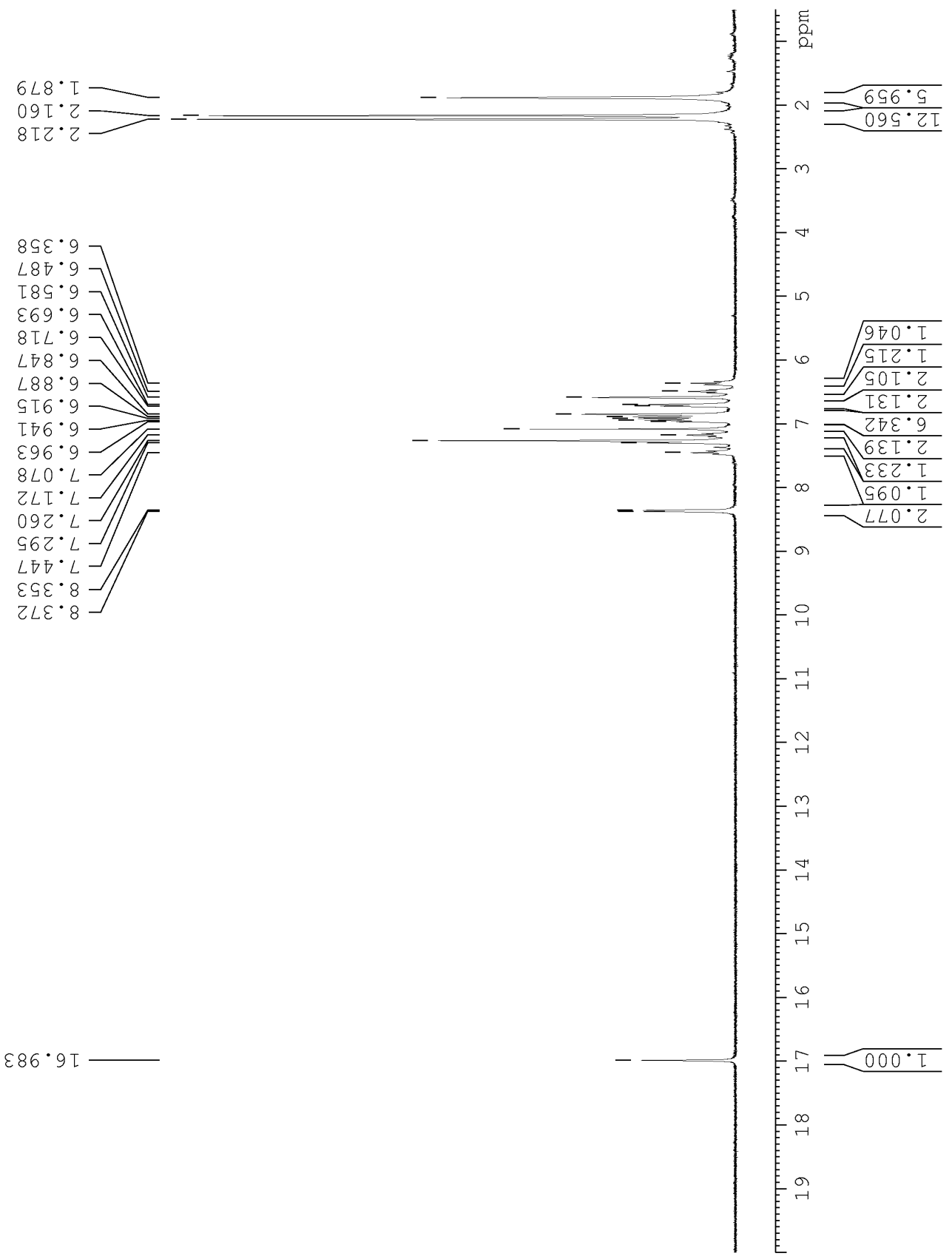


2b. ${ }^{13} \mathrm{C}\left\{{ }^{1} \mathrm{H}\right\}$ NMR spectrum of $6\left(75 \mathrm{MHz}, \mathrm{CDCl}_{3}\right)$
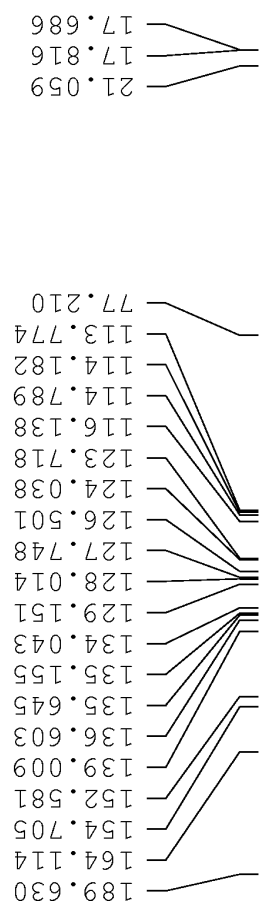

$0 \varepsilon 9 \cdot 68 \mathrm{~T}$

59ワ・ $\angle 82-$

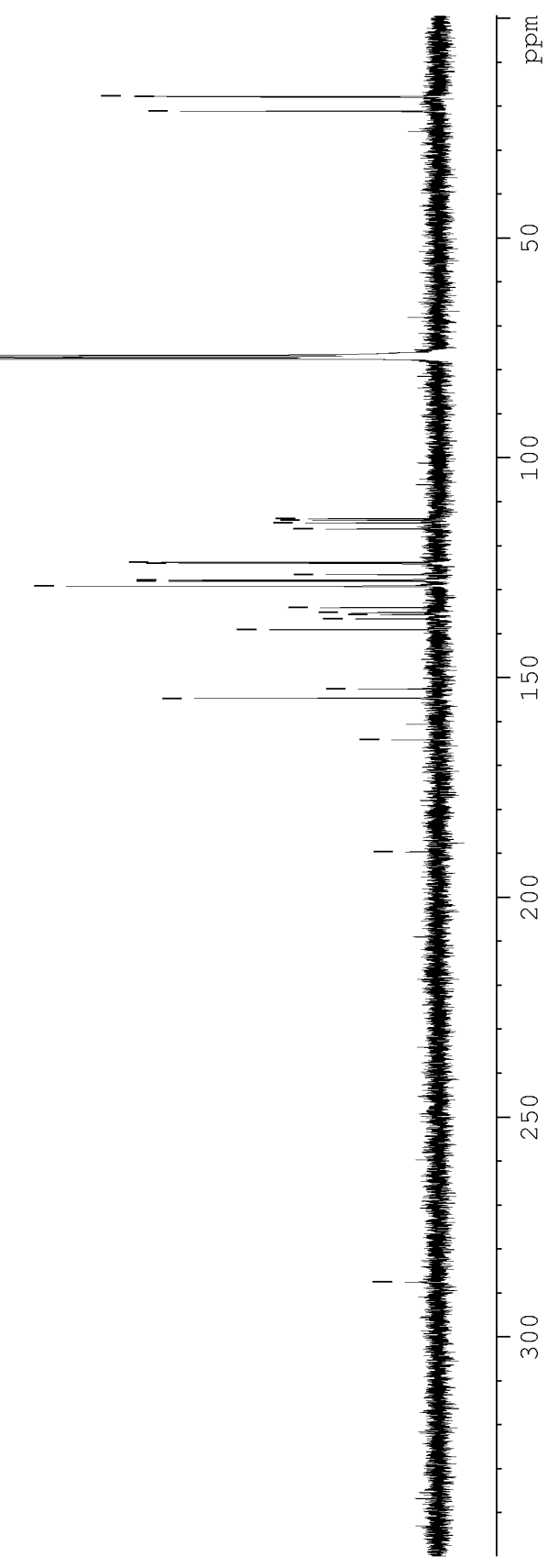

